\title{
INDICADORES CLIMÁTICOS DE DESERTIFICAÇÃO NA BACIA HIDROGRÁFICA DO RIO PAJEÚ, PERNAMBUCO
}

\author{
SOARES, Deivide Benicio- deividebenicio@yahoo.com.br \\ Universidade Federal do Pernambuco/ UFPE
}

\author{
NOBREGA, Ranyére Silva - ranyere.nobrega@yahoo.com.br \\ Universidade Federal do Pernambuco/ UFPE
GALVÍNCIO, Josiclêda Domiciano - josicleda@gmail.com Universidade Federal do Pernambuco/ UFPE

\begin{abstract}
RESUMO: Apesar do tema da desertificação ser estudado em âmbito internacional desde a década de 1970, o consenso sobre o assunto ainda é muito restrito, especialmente quando se trata da definição dos indicadores de desertificação. Desde a realização da Conferência das Nações Unidas sobre Desertificação em 1977, em Nairóbi, no Quênia, os indicadores de desertificação constituem tema de estudos e discussões tanto no meio acadêmico/científico, quanto no meio técnico, representado pelas entidades governamentais. Dentre os indicadores de desertificação acordados na atualidade estão os indicadores abióticos, representados pelos aspectos climáticos, edáficos e hídricos. Neste contexto está fundamentado o objetivo deste trabalho: analisar os indicadores climáticos de desertificação na bacia hidrográfica do rio Pajeú, buscando-se identificar tendência climática na precipitação, no índice de aridez e no índice de precipitação padronizada. Através da aplicação do teste de Mann-Kendall em séries históricas de pluviometria do período de 1965 a 2014 de 12 localidades, foram encontradas tendências negativas (de diminuição) com significância estatística de $95 \%$ para a precipitação e os índices de aridez e de precipitação padronizada de três postos pluviométricos situados na porção sul da bacia.
\end{abstract}

PALAVRAS-CHAVES: tendência climática; índice de aridez; índice de precipitação padronizada

INDICADORES CLIMÁTICOS DE DESERTIFICACIÓN EN LA CUENCA HIDROGRÁFICA DEL RÍO PAJEÚ, PERNAMBUCO

RESUMEN: A pesar que el tema de la desertificación de suelos viene siendo estudiado por la comunidad científica internacional desde la década del 1970, todavía no existe un consenso unificado sobre los criterios que rigen el asunto, especialmente en lo que se relaciona con los indicadores que definen estos procesos. Desde 1977 cuando fue realizada la Conferencia de las Naciones Unidas sobre desertificación en Nairobi (Kenia), dichos indicadores pasaron a constituir temas de investigación y discusión, tanto en el medio académico/científico como en el medio gubernamental. Entre los indicadores de desertificación discutidos en la actualidad están los climáticos, edáficos e hídricos. En este contexto está fundamentado el objetivo de este trabajo: analizar los indicadores climáticos de desertificación en la cuenca hidrográfica del río Pajeú, buscando identificar tendencia climática en la precipitación, en el índice de aridez y en el índice estandarizado de precipitación. A través de la aplicación de la prueba de Mann-Kendall en series históricas de pluviometría del período de 1965 a 2014 de 12 localidades, se encontraron tendencias negativas (de disminución) con significancia estadística del $95 \%$ para la precipitación y los índices de aridez y de precipitación estandarizada de tres estaciones pluviométricas situadas en la porción sur de la cuenca

PALABRAS CLAVE: tendencia climática; índice de aridez; índice estandarizado de precipitación. 


\title{
CLIMATIC INDICATORS OF DESERTIFICATION IN THE PAJEÚ WATERSHED, PERNAMBUCO
}

\begin{abstract}
Although the issue of desertification has been internationally studied since the 1970s, the consensus on the subject is still very small, especially when it comes to the definition of desertification indicators. Since the United Nations Conference on Desertification held in 1977 in Nairobi, Kenya, desertification indicators have been subject of studies and discussions in the academic / scientific community, as in technical environments, represented by government entities. Abiotic indicators are among desertification indicators recognized today, represented by climatic, edaphic and water aspects. In this context, the aim of this study was to analyze the climate desertification indicators in the Pajeú Watershed, looking for to identify climate trend in Rainfall, Aridity Index and Standardized Precipitation Index. By applying the Mann-Kendall test in historical series from 1965 to 2014 of 12 locations, negative trends (decrease) were found with statistical significance of $95 \%$ for precipitation and aridity indices and standardized precipitation in three rain gauge stations located in the southern portion of the basin.
\end{abstract}

KEYWORDS: climate trend; aridity index; standardized precipitation index.

\section{INTRODUÇÃO}

O tema desertificação constituiu importante pauta na Conferência do Meio Ambiente realizada em 1972 na cidade de Estocolmo, na Suécia e culminou, após esta, em uma conferência específica sobre o tema em 1977, a Conferência Mundial sobre Desertificação, realizada em Nairóbi, no Quênia. O assunto voltou a ser amplamente discutido na Rio-92, a Conferência do Meio Ambiente que ocorreu na cidade do Rio de Janeiro, no Brasil, em 1992. Em 1994 foi elaborada a "Convenção Internacional de Luta contra a Desertificação em Países Afetados por Seca Grave ou Desertificação, em particular na África" ou simplesmente Convenção das Nações Unidas de Combate à Desertificação, UNCCD.

Apesar do tema estar sendo estudado em âmbito internacional desde a década de 1970, o consenso sobre o assunto ainda é muito restrito, especialmente quando se trata da definição dos indicadores de desertificação. Matallo Júnior (2001) afirma que isso ocorre porque o conceito de desertificação não respeita o pensamento cartesiano, constituindo-se um conceito essencialmente transdisciplinar, em função das suas múltiplas causas e efeitos, o que força uma necessária, porém difícil, integração entre diferentes áreas e disciplinas científicas.

Em trabalho pioneiro no Brasil, Vasconcelos Sobrinho (1978) apresentou um manual de indicadores de desertificação no texto intitulado "Metodologia para identificação de processos de desertificação". Nesta publicação, o autor reuniu os indicadores de desertificação que foram consensos no Seminário sobre Desertificação e na Conferência das Nações Unidas sobre o mesmo tema, realizados em Nairóbi, nos meses de agosto e setembro de 1977 . Segundo o autor, o propósito deste seminário foi a definição de uma série integrada de indicadores críticos (físicos, biológicos-agrícolas e sociais) que servissem para diagnosticar o processo de desertificação e contribuíssem para a execução de programas corretivos. Desde então, os indicadores de desertificação continuaram sendo tema de estudos e discussões tanto no meio acadêmico/científico, quanto no meio técnico, representados pelas entidades governamentais. 
Abraham e Beekman (2006) destacam que no início da década de 1990 um grupo de pesquisadores e Organizações Não Governamentais (ONGs) do Brasil, Argentina, Chile, Peru e Bolívia, coordenados pela Fundação Esquel, desenvolveram um projeto com o objetivo de elaborar uma metodologia unificada para avaliação e monitoramento da desertificação na América Latina, apoiados desde o início pelo Programa Regional para América Latina e Caribe da UNCCD. Ainda segundo os autores, merece destaque na América Latina o trabalho precursor deste grupo, com o desenvolvimento de estudos nas regiões áridas e semiáridas, em especial na obtenção de indicadores de desertificação.

Em 2001, tiveram início as atividades do Programa de Luta Contra a Desertificação e Mitigação dos Efeitos da Seca na América do Sul, com a participação de seis países: Argentina, Bolívia, Brasil, Chile, Equador e Peru. Este programa motivou a elaboração dos Programas de Ação Nacionais (PAN) e promoveu avanços nos temas prioritários estabelecidos pela Conferência das Partes da Convenção das Nações Unidas de Luta contra a Desertificação e a Seca, dentre eles, a harmonização e aplicação dos indicadores de desertificação existentes, organizando-os em quatro grandes grupos: indicadores abióticos (relacionados ao clima, água e solo), indicadores bióticos (flora e fauna), indicadores sociais e econômicos e indicadores institucionais e organizacionais.

Dentre os indicadores climáticos de desertificação em consenso entre pesquisadores dos seis países membros do Programa de Luta Contra a Desertificação e Mitigação dos Efeitos da Seca na América do Sul estão o índice de aridez e o índice de precipitação padronizada. Desse modo, o objetivo deste trabalho consiste em identificar tendências climáticas nestes dois indicadores e na ocorrência de precipitação na bacia hidrográfica do rio Pajeú, no semiárido brasileiro.

\section{CARACTERIZAÇÃO DA ÁREA DE ESTUDO}

A área de estudo deste trabalho é a bacia hidrográfica do Rio Pajeú (Figura 1), a maior bacia de Pernambuco, com uma área de $16.838,70 \mathrm{~km} 2$, que corresponde a $17,02 \%$ da área do Estado (PERNAMBUCO, 1998). Está localizada, em sua totalidade, em Pernambuco, formando a Unidade de Planejamento Hídrico UP9, entre $7^{\circ} 6^{\prime} 20^{\prime \prime}$ e $8^{\circ} 56^{\prime} 01^{\prime \prime}$ de latitude sul, e 36059'00" e $38^{\circ} 57^{\prime} 45^{\prime \prime}$ de longitude a oeste de Greenwich.

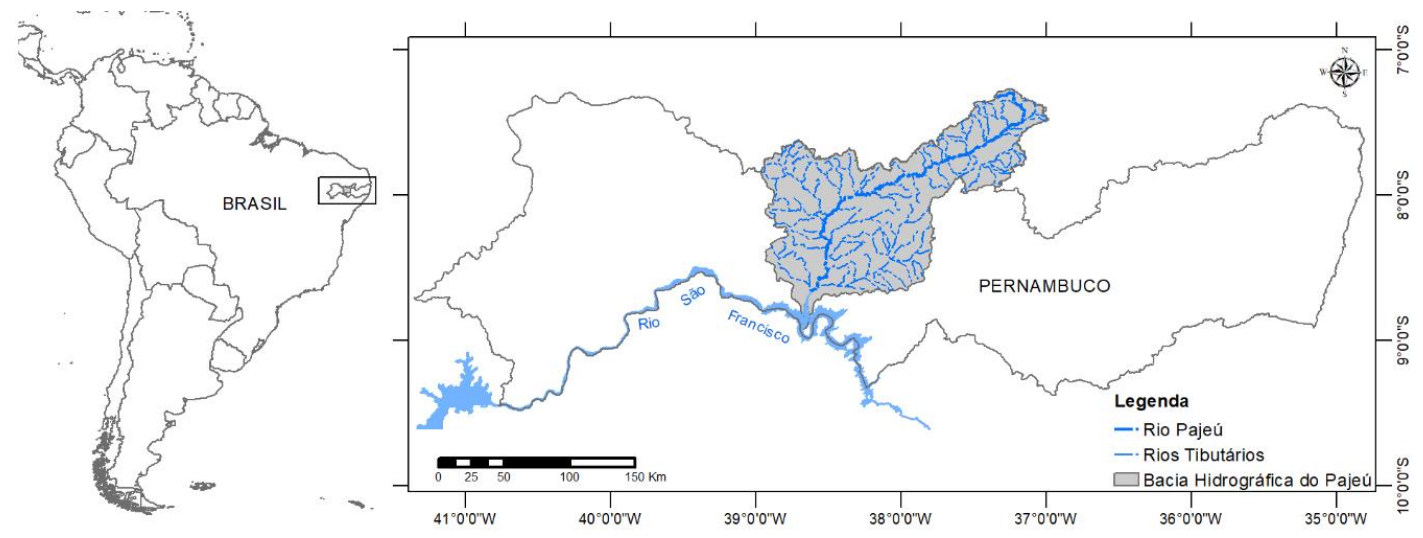

Figura 1 - Localização da bacia hidrográfica do Rio Pajeú. 2017 
Conforme se pode observar através da Figura 2, as médias históricas de precipitação nesta bacia são mais elevadas na porção norte, onde a influência da topografia propicia uma média anual superior a $1.200 \mathrm{~mm}$, e diminuem gradativamente em direção ao sul, com os menores valores médios anuais, como $467 \mathrm{~mm}$ no entorno do Rio São Francisco (Figura 2A). As normais climatológicas das temperaturas médias anuais também apresentam padrão de variação norte-sul (Figura $2 \mathrm{~B}$ ) e é possível observar que as médias históricas anuais de temperatura média variam de $20^{\circ} \mathrm{C}$ na porção norte, onde as cotas altimétricas ultrapassam os $900 \mathrm{~m}$, até os $26,2^{\circ} \mathrm{C}$ na porção sul, na calha do Rio São Francisco, cuja altitude média é de $350 \mathrm{~m}$. Há, portanto, duas regiões climaticamente distintas na bacia do Pajeú, a porção norte na qual, de maneira geral, chove mais e as temperaturas são mais amenas, e a porção sul na qual o clima é mais quente e seco.
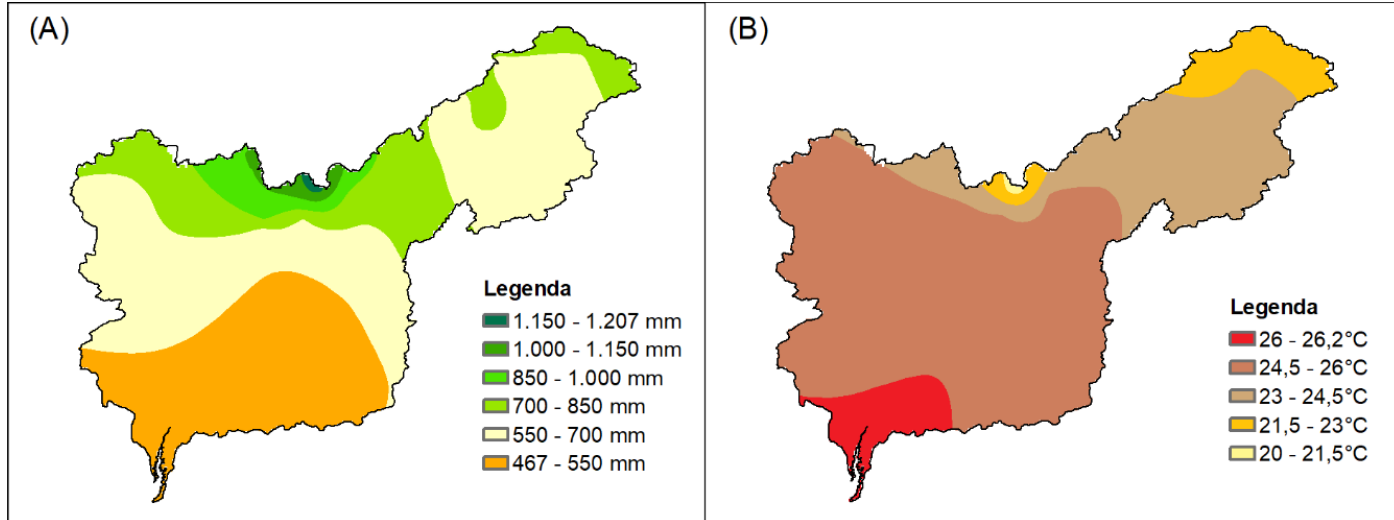

Figura 2 - Isoietas (A) e isotermas (B) da bacia hidrográfica do Pajeú. Fonte: Adaptado de Pernambuco (2006).

\section{MATERIAL E MÉTODOS}

Para identificação de tendência climática na precipitação, no índice de aridez e no índice de precipitação padronizada foram utilizados os valores mensais das séries históricas com 50 anos de dados, de 1965 a 2014, de 12 postos pluviométricos distribuídos na bacia do Pajeú (Figura 3). Estes dados são oriundos dos acervos da Agência Pernambucana de Águas e Clima (APAC) e Agência Nacional de Águas (ANA). 


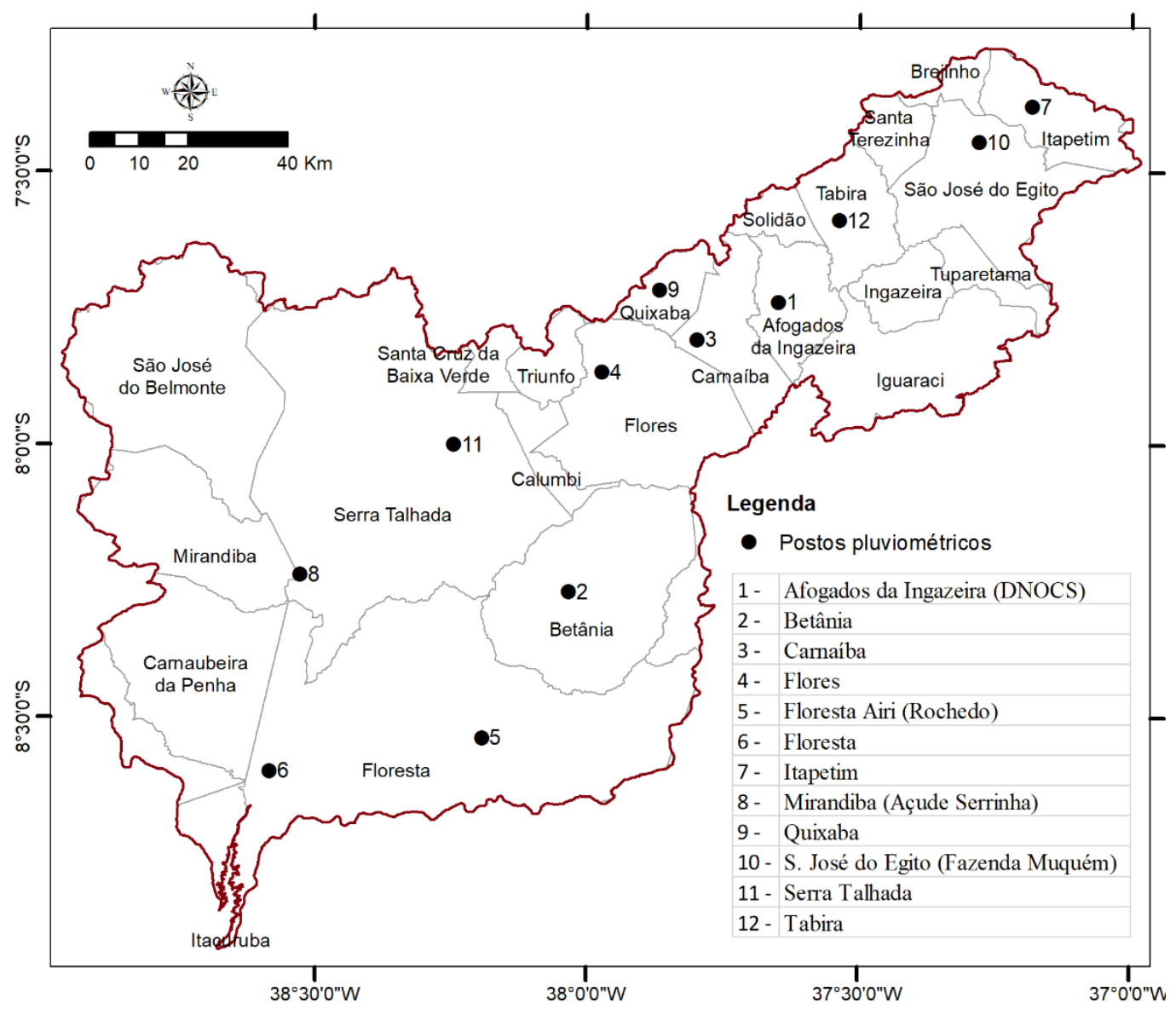

Figura 3 - Localização dos postos pluviométricos utilizados na pesquisa.

A identificação de tendência climática na precipitação foi realizada aplicando-se o teste não-paramétrico de Mann-Kendall, recomendado pela Organização Meteorológica Mundial como um dos principais métodos de estudo de tendências de mudanças climáticas (SENA; LUCENA, 2013; LOPES; SILVA, 2013; YUE et al., 2002;). Para execução do teste de Mann-Kendall foi utilizado o aplicativo ActionStat.

Inicialmente proposto por Mann (1945) e posteriormente alterado por Kendall (1975), que criou a correspondente estatística Mann-Kendall (MK), o teste MK consiste em comparar cada valor da série temporal com os valores restantes, sempre em ordem sequencial; é contado o número de vezes em que os termos restantes são maiores que o valor analisado. A estatística do teste é obtida pela soma de todas as contagens, como segue:

$$
\tau=\frac{S}{\left(\frac{n}{2}\right)}
$$

em que n é o número da amostra e S é a pontuação de Kendall (1975), dada por 


$$
S=\sum_{i=2}^{n} \sum_{j=1}^{i-1} \operatorname{sinal}\left(x_{i}-x_{j}\right)
$$

em que $x j$ são os dados estimados da sequência de valores, $n$ é o número de elementos da série temporal e o sinal $(x i-x j)$ é igual a -1 para $(x i-x j)<0,0$ para $(x i-x j)=0$, e 1 para $(x i-x j)>0$.

Kendall (1975) mostrou que $S$ é normalmente distribuída com média $E$ (S) e variância $\operatorname{Var}(\mathrm{S})$ e que para uma situação na qual pode haver valores iguais de $x$, são calculadas pelas equações:

$$
\begin{gathered}
E(S)=0 \\
\operatorname{Var}(S)=\frac{1}{18}[n(n-1)(2 n+5)]
\end{gathered}
$$

Assim, o teste estatístico ZMK é dado por:

$$
Z_{M K}=\left\{\begin{array}{l}
\frac{S-1}{\sqrt{\operatorname{Var}(S)}} \text {, se } S>0 \\
0, \quad \text { se } S=0 \\
\frac{S+1}{\sqrt{\operatorname{Var}(S)}} \text {, se } S<0
\end{array}\right.
$$

A presença de tendência estatisticamente significativa na série temporal é avaliada através do valor de ZMK; esta estatística é usada para testar a hipótese nula de que nenhuma tendência existe. Os valores positivos (negativos) de ZMK indicam tendência crescente (decrescente).

Segundo Goossens e Berger (1986) o teste de Mann Kendall é o método mais apropriado para realizar análise de mudanças climáticas em séries climatológicas, possibilitando ainda, a detecção do ponto inicial da tendência. Este teste foi bastante aplicado por McLeod et al., (1990) e Hipel e McLeod (1994) em análises de vários tipos de dados ambientais. Modares e Silva (2007) afirmaram que o teste de Mann-Kendall avalia com bastante eficiência a tendência em séries temporais de dados ambientais.

No Brasil, esse teste vem sendo empregado para análise de tendências em diversas variáveis ambientais, como séries temporais de precipitação, temperatura, umidade, radiação solar e vazão de rios (ALMEIDA et al., 2014; GARCIA; PENEREIRO, 2013; SILVA et al., 2013; FERRARI; VECCHIA; COLABONE, 2012; BLAIN, 2010; SILVA et al., 2010).

Neste trabalho foi seguida a recomendação de Marengo et al., (2007), que utilizaram o nível de significância $a=0,05$ (significância estatística de 95 $\%$ ) em estudos de tendência climática. Assim, a hipótese HO (tendência nula) é aceita quando o $\mathrm{p}$-valor calculado no teste for maior que 0,05 . Por outro lado, a hipótese nula é rejeitada sempre que o p-valor calculado pelo teste for menor que 0,05 - nestes casos a hipótese da tendência é considerada verdadeira. 
Adotou-se o índice de aridez (IA) utilizado no contexto da Convenção das Nações Unidas de Combate à Desertificação (UNCCD), que é representado pela razão entre a precipitação $(P)$ e a evapotranspiração (ETP), o qual é tomado como parâmetro para delimitação das regiões áridas: $(0,05<\mathrm{IA}<0,20)$, semiáridas $((0,20<$ IA $<0,50)$ e subúmidas secas $(0,50<$ IA $<0,65)$, conforme bem destacado por Brasil (2005) e Pernambuco (2009), não correspondendo, portanto ao índice de aridez de Thornthwaite $(1941 ; 1933$; 1931). O cálculo do IA foi realizado no Microsoft Excel.

Os dados de precipitação $(P)$ foram retirados das séries históricas dos 12 postos pluviométricos distribuídos na bacia do Pajeú (Figura 3). Já os dados da evapotranspiração (ETP) foram obtidos por estimativa através do método proposto por Rolim, Sentelhas e Barbieri (1998), que elaboraram uma planilha no ambiente Microsoft Excel para calcular o balanço hídrico de Thorntwaite e Mather (1955).

Além dos dados de precipitação, para calcular o balanço hídrico e obter a estimativa de evapotranspiração, foram utilizados como dados de entrada valores de temperatura média mensal estimados para cada ano através do programa Estima_T-2.0 (CAVALCANTI; SILVA; SOUSA, 2006). Foi necessário estimar a temperatura em função de não haver registros de temperaturas médias mensais do ar nestas localidades para o período estudado.

O índice de precipitação padronizada (IPP), desenvolvido por McKee, Doesken e Kleist (1993) foi concebido para quantificar o déficit de precipitação para várias escalas temporais, as quais refletem o impacto da seca na disponibilidade dos diferentes recursos hídricos. As condições de umidade do solo respondem a anomalias de precipitação em uma escala relativamente curta. As anomalias de precipitação a longo prazo são refletidas nas águas subterrâneas, no volume das águas fluviais e no armazenamento nos reservatórios. Por isso, originalmente o índice de precipitação padronizada foi calculado para as escalas temporais de 3, 6, 12, 24 e 48 meses, mas este índice pode ser calculado para outros intervalos, desde 1 mês até 72 meses (WMO, 2012). Neste trabalho adotou-se, apenas, o IPP de 12 meses (SPI-12), que é uma comparação da precipitação de 12 meses consecutivos com a registrada nos mesmos 12 meses consecutivos de todos os anos precedentes.

McKee, Doesken e Kleist (1993), utilizaram o sistema de classificação mostrado na Tabela 1 para definir as diferentes intensidades de seca segundo os distintos valores de IPP. Também definiram os critérios para os episódios de seca em todas as escalas temporais. Um episódio de seca é detectado sempre que o IPP seja continuamente negativo e alcance uma intensidade menor ou igual a $-1,0$. Este episódio de seca finaliza quando o IPP alcança valores positivos. Consequentemente, todos os episódios de seca têm uma duração definida por seu começo e seu final e uma intensidade para cada mês em que continua a seca.

Para o cálculo do IPP foi utilizado o software SPI_SL_6.exe, o qual requer um arquivo de texto sem formatação (.txt) com o nome do posto pluviométrico e três colunas de informação contendo o ano, o mês (indicado pelo número de 1 a 12) e o valor da precipitação observada em cada mês. Como dado de entrada foram inseridas as séries pluviométricas de 1965 a 2014 (50 anos) dos 12 postos apresentados na Figura 3.

Tabela 1 - Escala de valores do índice de precipitação padronizada (IPP). 


\section{IPP Caracterização do período}

\begin{tabular}{cc}
\hline $\begin{array}{c}\text { Maior ou igual a 2,0 } \\
1,5 \text { a } 1,99\end{array}$ & $\begin{array}{c}\text { Extremamente úmido } \\
\text { Muito úmido }\end{array}$ \\
$-0,99$ a 1,49 & $\begin{array}{c}\text { Moderadamente úmido } \\
\text { Normal ou aproximadamente } \\
\text { normal }\end{array}$ \\
$-1,0$ a $-1,49$ & Moderadamente seco \\
$-1,5$ a $-1,99$ & Severamente seco \\
Menor ou igual a $-2,0$ & Extremamente seco \\
\hline
\end{tabular}

\section{RESULTADOS E DISCUSSÃO}

Dentre as localidades estudadas, dez apresentaram tendência negativa (Tabela 2), das quais três localidades apresentaram tendência negativa com significância estatística de $95 \%$, indicada pelo $p$-valor < 0,05, podendo ser consideradas hipóteses verdadeiras. Por outro lado, apenas as localidades de Afogados da Ingazeira e Tabira apresentaram tendências positivas nas três variáveis estudadas, porém o nível de significância estatística ficou muito abaixo de $95 \%$, podendo-se considerar hipótese nula.

Os postos pluviométricos cujas séries apresentaram tendência de diminuição da precipitação, do IA e do IPP-12 com alta significância estatística (acima de $95 \%$ ), foram Betânia, Mirandiba/Açude Serrinha e Floresta, as quais estão situadas na porção sul da bacia hidrográfica do Pajeú, como pode ser visto na Figura 4.

Tabela 2 - Tendências da precipitação, do índice de aridez (IA) e do índice de precipitação padronizada (IPP-12) nas séries históricas de 1965 a 2014 na bacia do Pajeú.

\begin{tabular}{|c|c|c|c|c|c|c|c|}
\hline Núm. & Posto & $\begin{array}{l}\text { Tendência } \\
\text { da Precip. }\end{array}$ & P-Valor & $\begin{array}{c}\text { Tendência } \\
\text { do IA } \\
\end{array}$ & P-Valor & $\begin{array}{c}\text { Tendência } \\
\text { do SPI }\end{array}$ & P-Valor \\
\hline 1 & Afogados da Ingazeira/Dnocs & 0,037 & 0,71 & 0,012 & 0,91 & 0,041 & 0,68 \\
\hline 2 & Betânia & $-0,206$ & $0,04 *$ & $-0,228$ & $0,02 *$ & $-0,204$ & $0,04 *$ \\
\hline 3 & Carnaíba & $-0,104$ & 0,29 & $-0,120$ & 0,22 & $-0,104$ & 0,29 \\
\hline 4 & Flores & $-0,164$ & 0,09 & $-0,187$ & 0,06 & $-0,164$ & 0,09 \\
\hline 5 & Floresta/Airi-Rochedo & & 0,42 & & & & 0,43 \\
\hline 6 & Floresta & $-0,276$ & $0,005^{*}$ & $-0,301$ & $0,002 *$ & $-0,276$ & $0,005 *$ \\
\hline 7 & Itape & & 0,07 & & 4* & $-0,180$ & 0,07 \\
\hline 8 & Mirandiba/Açude Serrinha & -0, & 0,0 & -0 , & 4* & $-0,251$ & $0,01 *$ \\
\hline 9 & Quixaba & $-0,068$ & 0,49 & $-0,099$ & 0,32 & $-0,067$ & 0,50 \\
\hline 10 & São José do Egit & $-0,0$ & & & & & 0,37 \\
\hline 11 & Serra Talhada & $-0,094$ & 0,34 & $-0,122$ & 0,22 & $-0,093$ & 0,34 \\
\hline 12 & Tabira & 0,066 & 0,50 & 0,040 & 0,69 & 0,068 & 0,49 \\
\hline
\end{tabular}

*Significância Estatística de 95 \%. 


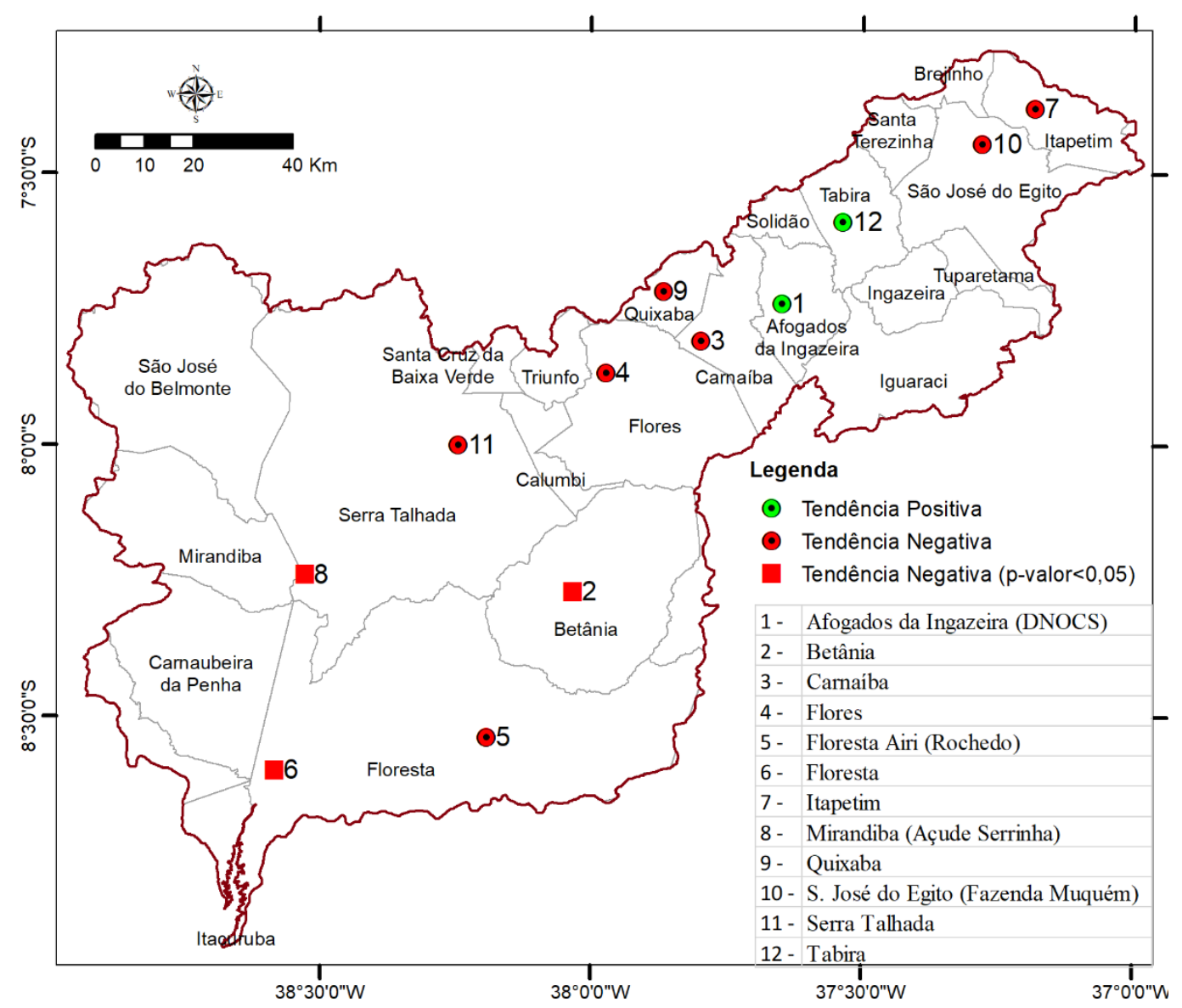

Figura 4 - Espacialização da tendência apresentada pela precipitação: IA e IPP-12.

Algumas colocações podem ser feitas com base nos resultados apresentados: a tendência negativa da precipitação mostra que o volume anual de chuva está diminuindo; com a tendência negativa, a redução dos valores do IA podem indicar uma mudança da categoria do semiárido (IA entre 0,20 e 0,50 ) para o árido (IA entre 0,05 e 0,20 ) e a tendência de diminuição dos valores do IPP ilustra que os episódios de seca estão se tornando mais severos, pois quanto menor o IPP, mais extrema e rigorosa é a seca. Os valores apresentados pelo teste de tendência nas três variáveis, portanto permitem afirmar que na porção sul da bacia do Pajeú o clima está se tornando mais seco.

Duas questões adquirem relevância diante destes resultados. Em primeiro lugar, a partir dos mapas das isoietas e isotermas (Figura 2) foi visto que há duas regiões distintas na bacia do Pajeú, a porção norte onde, de maneira geral, chove mais e as temperaturas são mais amenas e a porção sul, onde o clima é mais quente e seco. A segunda questão está relacionada ao índice de aridez médio do Pajeú (Figura 5), através do qual é possível observar que na porção sul são encontradas as menores médias do índice de aridez e quanto menor o valor do índice de aridez, mais seco é o clima. 


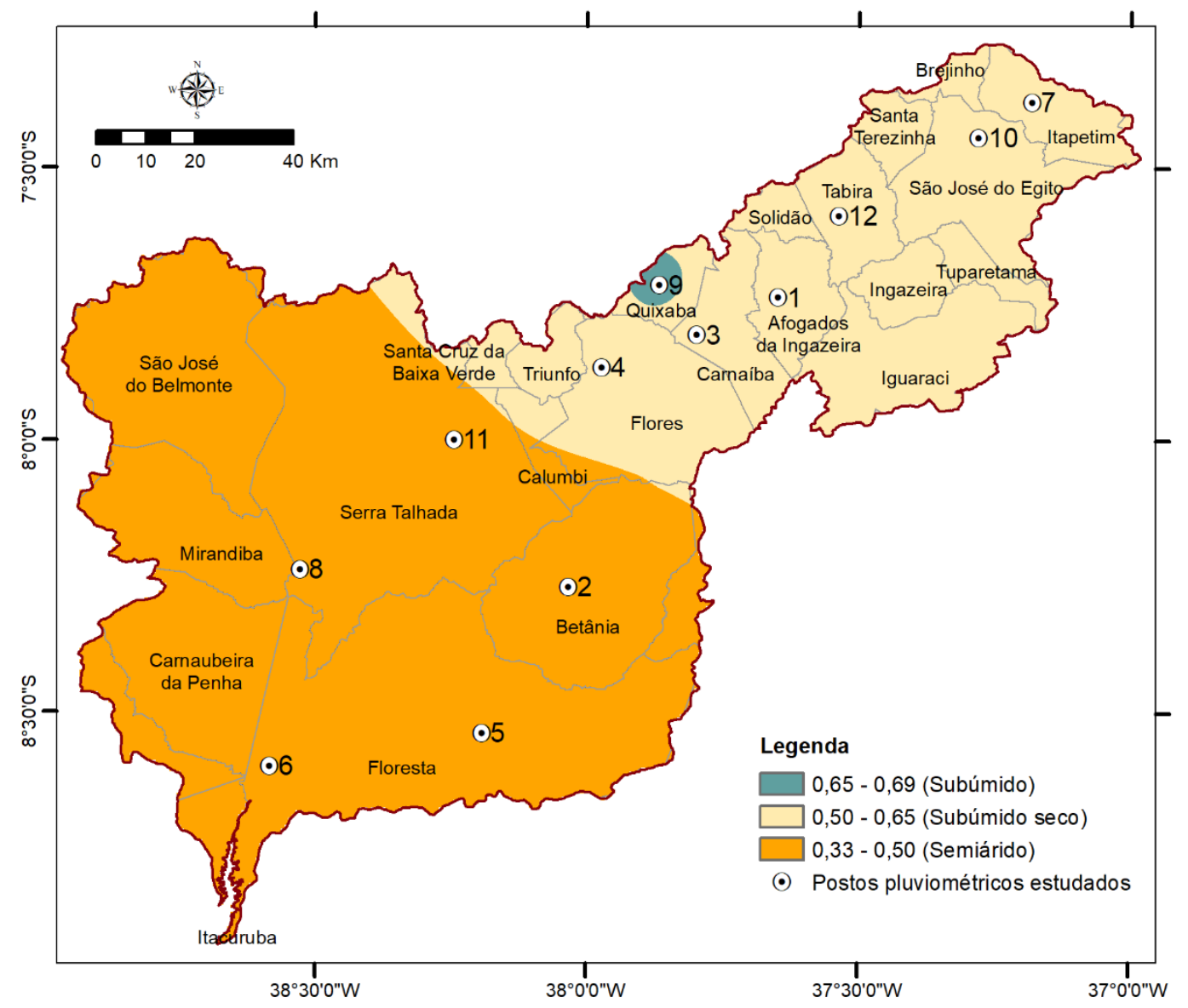

Figura 5 - Índice de Aridez média da bacia interpolado a partir da espacialização dos valores médios das 12 localidades estudadas na bacia do Pajeú.

A seguir serão apresentados os gráficos com as tendências das variáveis precipitação, índice de aridez e índice de precipitação padronizada dos postos de Betânia, Floresta e Mirandiba/Açude Serrinha, os quais geraram resultados com alta significância estatística. 

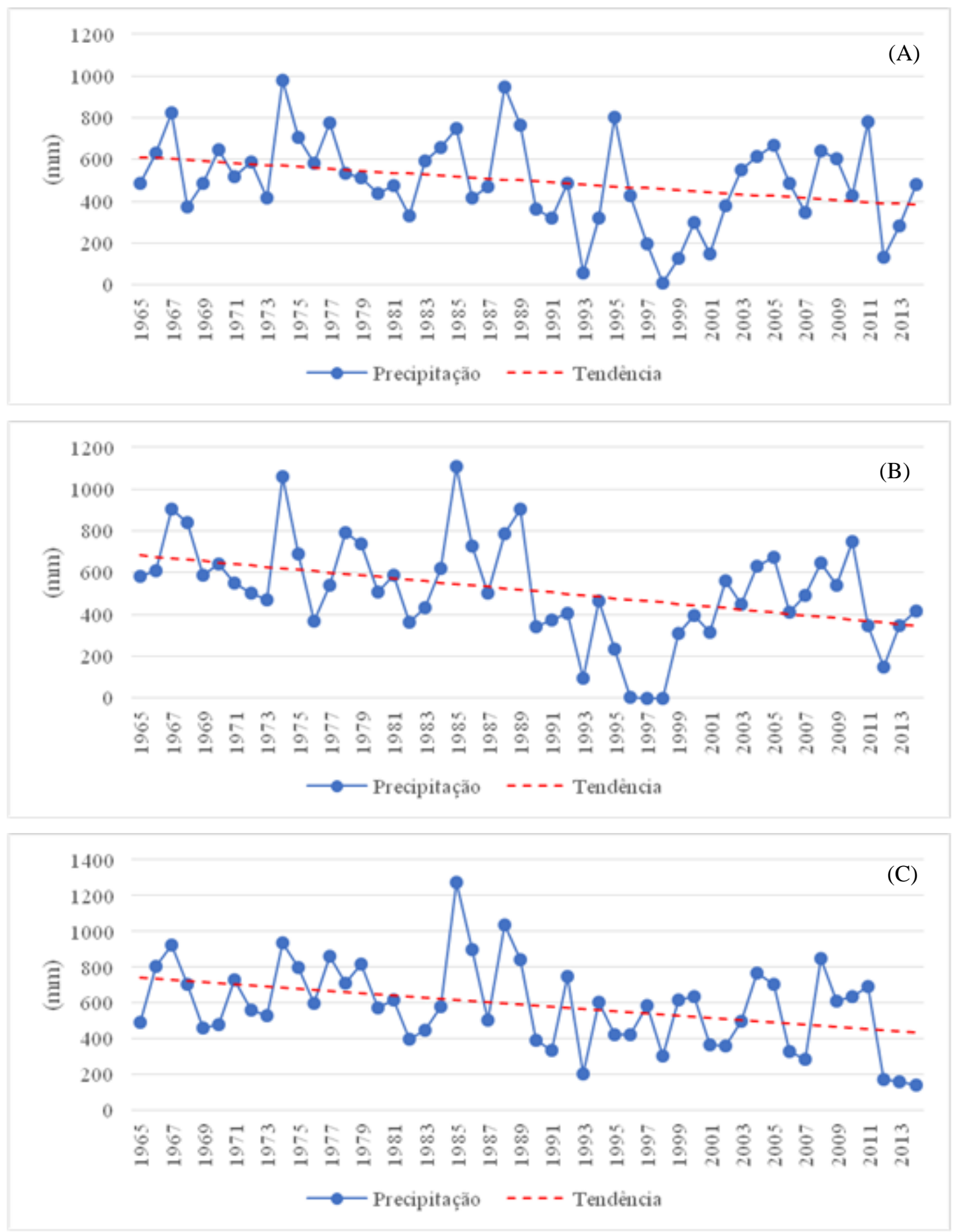

Figura 6 - Tendência da precipitação nos postos pluviométricos de Betânia (A), Floresta (B) e Mirandiba/Açude Serrinha (C). 

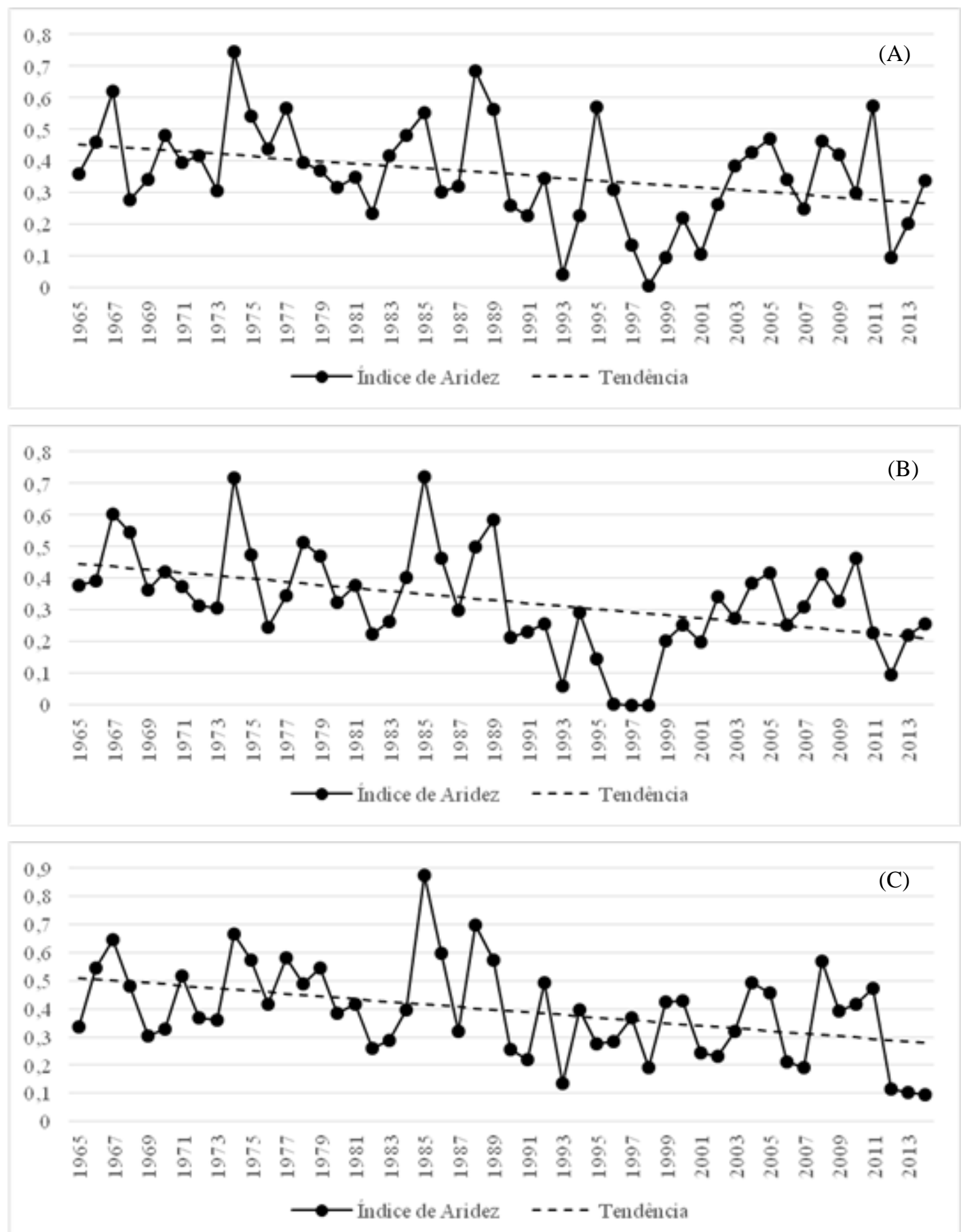

Figura 7 - Tendência do índice de aridez nos postos pluviométricos de Betânia (A), Floresta (B) e Mirandiba/Açude Serrinha (C). 


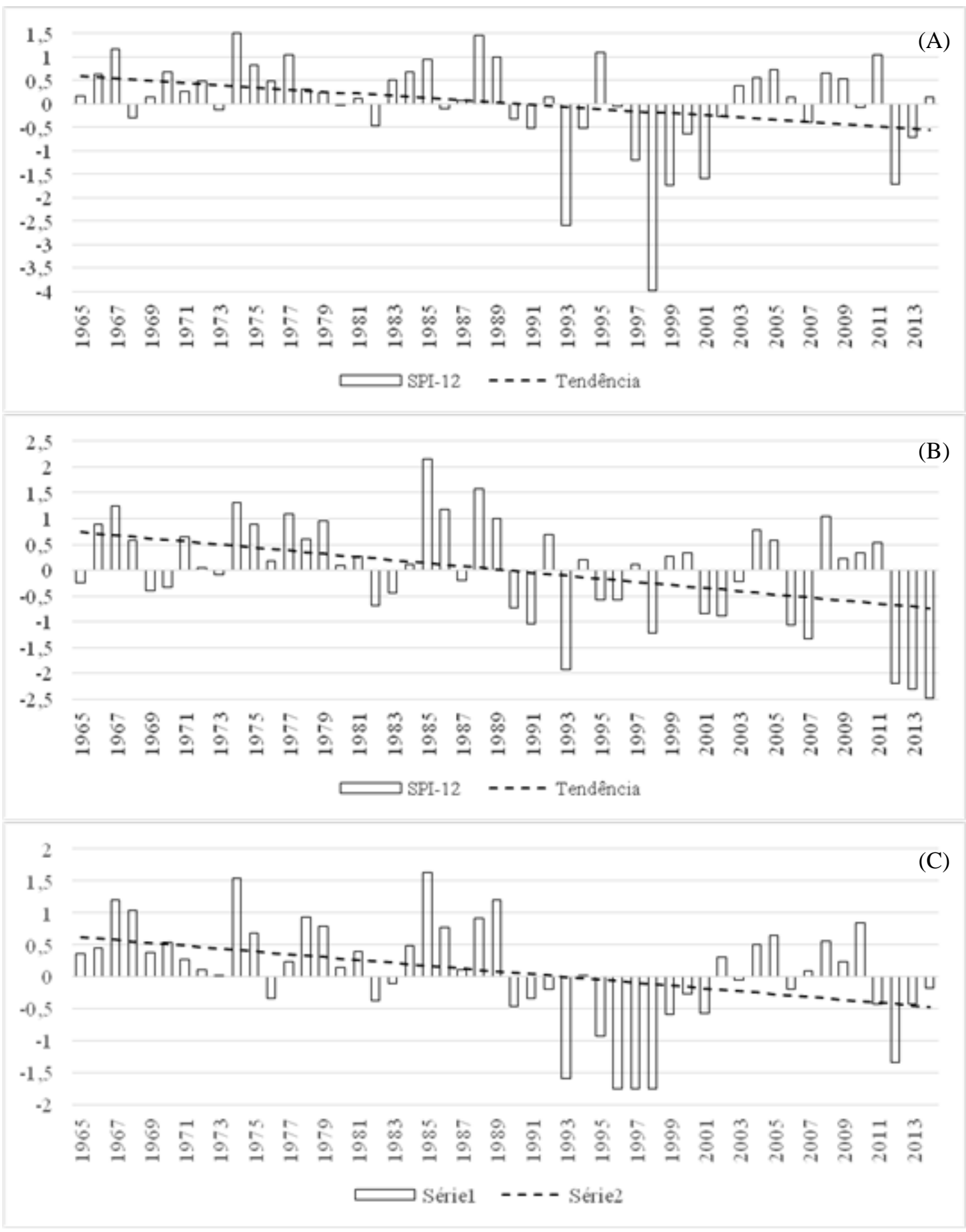

Figura 8 - Tendência do índice de precipitação padronizada nos postos pluviométricos de Betânia (A), Floresta (B) e Mirandiba/Açude Serrinha (C).

Não se pode esperar comportamento homogêneo das chuvas ao longo dos 50 anos comparando-se as séries de pluviometria destas três localidades. Em primeiro lugar, deve-se levar em conta que as chuvas se distribuem espacialmente de maneira irregular no semiárido brasileiro, sendo comum em um mesmo episódio de chuva serem registrados diferentes totais de 
precipitação em municípios vizinhos. A outra questão que se deve atentar é, justamente, a distância entre os citados postos pluviométricos. Apesar de estarem os três na porção sul da bacia, a distância mínima entre eles é $40 \mathrm{~km}$.

Todavia, é possível identificar algum padrão de comportamento similar na distribuição da pluviometria nas três séries analisadas. Neste sentido, uma observação a ser feita é que as máximas precipitações foram registradas na primeira metade da série (entre 1965 e 1989), enquanto os mínimos valores de pluviometria foram registrados após 1990 nas três localidades.

A distinção entre as duas metades das séries analisadas fica evidenciada ao se observar os gráficos com a distribuição dos valores do IPP-12, através dos quais nota-se que há uma maior quantidade de anos com IPP de sinal positivo nos primeiros 25 anos das séries das três localidades, ao passo que a partir de 1990 há uma maior frequência da ocorrência de anos com IPP negativo, se configurando como um período mais seco.

Outra questão comum às três localidades analisadas é que a quantidade de anos considerados severamente secos (IPP entre -1,5 e -1,99) e extremamente secos (IPP menor ou igual a -2) é maior do que a quantidade de anos muito úmidos (IPP entre 1,5 e 1,99) e extremamente úmido (IPP maior ou igual a 2). Além disso, só se observaram anos muito ou extremamente úmidos entre os anos de 1965 e 1989, ao mesmo tempo em que só foram observados anos severamente ou extremamente secos após 1990.

Os únicos anos considerados muito ou extremamente úmidos ao menos em uma das séries analisadas foram 1974, 1985 e 1988. Nestes anos evidenciaram-se episódios de La Niña - de intensidade forte em 1974 e 1988, e de intensidade fraca em 1985 - e registrou-se fase negativa do Dipolo do Atlântico em 1974 e 1985. Já os anos considerados severamente ou extremamente secos em pelo menos uma das séries foram os anos de 1993, 1996, 1997, 1998, 1999, 2001, 2012, 2013 e 2014. Em alguns destes anos ocorreram eventos de El Niño de intensidade forte e se configurou a fase positiva no Padrão Dipolo do Atlântico.

As anomalias térmicas dos oceanos Pacífico (El Niño/La Niña) e Atlântico Tropical (Padrão Dipolo) exercem influência sobre a ocorrência de chuvas acima ou abaixo da média na região Nordeste do Brasil, (NÓBREGA; SANTIAGO; SOARES, 2016). Marengo, Druyan e Hastenrath (1993) afirmaram que durante anos de El Niño a Zona de Convergência Intertropical encontra-se anomalamente mais ao norte de sua posição normal, assim os ventos alísios de SE e NE sopram com menos intensidade, reduzindo, assim, a umidade que penetra no Nordeste do Brasil. Já em anos de La Niña, o que se observa, de uma maneira geral, é aumento das precipitações sobre esta região, (KAYANO; ANDREOLI, 2009).

Nas fases positivas do Padrão Dipolo do Atlântico, em que as temperaturas são mais elevadas no Atlântico Norte, há uma redução das chuvas no nordeste do Brasil, enquanto as fases negativas, cujas temperaturas estão mais frias no Atlântico Norte e mais aquecidas no Atlântico Sul, favorecem a ocorrência de precipitação acima da média no Nordeste do Brasil, (ANDREOLI e KAYANO, 2007; MOURA e SHUKLA, 1981; HASTENRATH e HELLER, 1977).

Outros estudos de tendência climática realizados a partir de séries pluviométricas de postos localizados na bacia do Pajeú encontraram resultados 
semelhantes aos aqui apresentados. Lacerda, Melo e Soares (2009) identificaram tendência negativa de precipitação em oito estações pluviométricas da bacia o Pajeú, dentre as quais duas apresentaram significância estatística de 95 \%. Assis, Sobral e Souza (2012) também identificaram tendência negativa na ocorrência de precipitação da bacia do Pajeú e na bacia do rio Brígida, também situada no semiárido pernambucano.

Não há, porém, unanimidade nos resultados dos testes de tendência climática em outras áreas do Nordeste do Brasil. Em estudo realizado no estado do Ceará, Moncunill (2006) encontrou o predomínio de tendência negativa na precipitação, no período de 1974 a 2003, em 27 de 32 estações pluviométricas analisadas. Por outro lado, Santos et al., (2009), ao analisar as séries de pluviometria de 18 localidades no Ceará, encontrou tendência de aumento na precipitação total em 12 das séries analisadas.

Santos e Brito (2007) também identificaram tendência de aumento na precipitação total em séries de pluviometria dos estados da Paraíba e do Rio Grande do Norte e ao analisar a tendência na ocorrência de precipitação sobre a região do Cariri Paraibano, Sena e Lucena (2013) encontraram tendência positiva com alta significância estatística (95\%).

Para o estado de Sergipe, Félix et al., (2010) identificaram tendência positiva na precipitação das microrregiões da Grande Aracaju, Médio Sertão e Central, porém na microrregião do Alto Sertão Sergipano foi identificada tendência negativa.

\section{CONCLUSÕES}

Em três localidades situadas na parte sul da bacia hidrográfica do rio Pajeú foram observadas tendências negativas na precipitação, no índice de aridez e no índice de precipitação padronizada com alta significância estatística ( $p$-valor $<0,05)$, demonstrando que esta região próxima ao rio São Francisco tende a se tornar mais seca.

Os volumes anuais de precipitação estão diminuindo, os episódios de seca estão se tornando mais severos e está havendo uma tendência de mudança de categoria do clima semiárido (IA entre 0,20 e 0,50) para o árido $(\mathrm{IA}<0,20)$ na porção sul da bacia do Pajeú.

\section{AGRADECIMENTOS}

O primeiro autor agradece à Coordenação de Aperfeiçoamento de Pessoal de Nível Superior (CAPES) pela bolsa de doutorado, fundamental para o desenvolvimento da pesquisa, bem como à Fundação de Amparo à Ciência e Tecnologia de Pernambuco (FACEPE) pela bolsa de fixação de pesquisador concedida, que garante a continuidade das pesquisas em meio acadêmico.

\section{REFERÊNCIAS}

ABRAHAM, E. M.; BEEKMAN, G. B. Indicadores de la Desertificación para América del Sur. Mendoza-Argentina: LaDyOt-IADIZA-CONICET, 2006. 
ALMEIDA, B. M.; JOSÉ, J. V.; DUARTE, S. N.; FRIZZONE, J. A.; ARRAES, F. D. D.; PERBONI, A. Análise de tendência temporal da precipitação diária máxima no Estado de São Paulo. Water Resources and Irrigation Management, v.3, n.1, p.1-12, 2014.

ANDREOLI, R.V.; KAYANO, M.T. A importância relativa do Atlântico Tropical Sul e Pacífico Leste na variabilidade de precipitação do Nordeste do Brasil. Revista Brasileira de Meteorologia, v. 22, n.1, p.63-74, 2007.

ASSIS, J. M. O.; SOBRAL, M. C. M.; SOUZA, W. M. Análise de Detecção de Variabilidades Climáticas com Base na Precipitação nas Bacias Hidrográficas do Sertão de Pernambuco. Revista Brasileira de Geografia Física, v.3, p.630-645, 2012

BLAIN, G. C. Detecção de tendências monótonas em séries mensais de precipitação pluvial do Estado de São Paulo. Bragantia, v. 69, n. 4, p1027-1033, 2010.

BRASIL. Programa de Ação Nacional de Combate à Desertificação e Mitigação dos Efeitos da Seca PAN-Brasil. Brasília, 2005.

CAVAlCANTI, E. P.; SILVA, V. P. R.; SOUSA, F. A. S. Programa computacional para a estimativa da temperatura do ar para a região Nordeste do Brasil. Revista Brasileira de Engenharia Agrícola e Ambiental, v. 10, n. 1, p. 140-147, 2006.

FÉLIX, D. O.; DE SOUSA, I. F.; NASCIMENTO, P. J. S. S.; SANTOS, D. N. Avaliação da Tendência de Precipitação Pluviométrica Anual no Estado de Sergipe. In: XVI CONGRESSO BRASILEIRO DE METEOROLOGIA, 16., 2010, Belém. Anais... Belém: UFPA, 2010.

FERRARI, A. L.; VECCHIA, F. A. S.; COLABONE, R. O. Tendência e variabilidade anuais da temperatura e da pluviosidade em Pirassununga-SP. Revista Brasileira de Climatologia, v. 10, p. 30-46, 2012.

GARCIA, V. F. V.; PENEREIRO, J, C. Implementações de softwares para análises de tendência temporal em dados de temperaturas, precipitações e vazões de rios para algumas localidades paulistas. In: ENCONTRO DE INICIAÇÃO EM DESENVOLVIMENTO TECNOLÓGICO E INOVAÇÃO, 3., 2013, Campinas. Anais... Campinas: PUC-Campinas, 2013.

GOOSSENS, C; BERGER, A. Annual and seasonal climatic variations over the northern hemisphere and Europe during the last century. Annales Geophysicae, v.4, p. $385-400,1986$

HASTENRATH, S.; HELLER, L. Dynamics of climatic hazards in Northeast Brazil. Quartely Journal Royal Meteorological Society, v.103, n.435, p.77-92, 1977.

HIPEL, K. W.; MCLEOD, A. I. Time Series Modelling of Water Resources and Environmental Systems. Amsterdam: Elsevier, 1994.

KAYANO, M. T.; ANDREOLI, R. V. Clima da Região Nordeste do Brasil. In: CAVALCANTI, I. F. A. et al. (Orgs.). Tempo e clima no Brasil. São Paulo: Oficina de Textos, 2009.

LACERDA, F. F.; MELO, A. V. P. V.; SOARES, D. B. Análise preliminar na deteç̧ão de tendências no padrão pluviométrico na Bacia do Pajeú - PE: 
Mudanças climáticas ou variabilidade?, In: SIMPÓSIO BRASILEIRO DE RECURSOS HÍDRICOS, 18., 2009, Campo Grande-MT. Anais..., CD Room, 2009.

LOPES, J. R. F.; SILVA, D. F. Aplicação do teste de Mann-Kendall para análise de tendência pluviométrica no Estado do Ceará. Revista de Geografia (UFPE), v. 30, n. 3, p. 192-208, 2013.

MARENGO, J.; NOBRE, C.; RAIGOZA, D.; VALVERDE, M.; PISNITCHENKO, I.A.; OLIVEIRA, J.C.M. Boletim do Projeto: uso de cenários de mudanças climáticas regionais em estudos de vulnerabilidade e adaptação no Brasil e na América do Sul (GOF-UK-CPTEC), 2007. Disponível em: <http://mudancasclimaticas.cptec.inpe.br/ rmclima/pdfs/newsletters/Newslette r_No4_Port.pdf >. Acesso em: 15 set. 2016.

MARENGO, J., DRUYAN, L., HASTENRATH, S. Observational and modelling studies of Amazonia interannual climate variability. Climatic Change, v. 23, n.3, p.267-286, 1993.

MATALLO JUNIOR, H. Indicadores de desertificação: histórico e perspectivas. Brasília: UNESCO, 2001.

MCKEE, T.B; DOESKEN, N.J.; KLEIST, J. The relationship of drought frequency and duration to time scale. Proceedings of the Eighth Conference on Applied Climatology, Anaheim, California, 17-22 January 1993. Boston, American Meteorological Society, 179-184, 1993.

MCLEOD, A.I.; HIPEL, K.W.; BODO, B.A. Trend analysis methodology for water quality time series. Environmetrics, v.2, p. 169-200, 1990.

MODARES, R.; SILVA, V. P. R. Trends analysis of rainfall record in arid and semiarid regions of Iran. Journal of Arid Environments, v.70, n.1, p.344-355, 2007.

MONCUNILL, D. F. The rainfall trend over Ceará and its implications. In: Conferência Internacional de Meteorologia e Oceanografia do Hemisfério Sul, 8., 2006, Foz do Iguaçu. Anais..., Foz do Iguaçu, 2006.

MOURA, A. D.; SHUKLA, J. On the Dynamics of Droughts in Northeast Brazil: Observations, Theory and Numerical Experiments with a General Circulation Model. Journal of the Atmospheric Science, v. 38, n. 12, p. 2653-2675. 1981.

NOBREGA, R. S.; SANTIAGO, G. A. C. F.; SOARES, D. B. Tendências do controle climático oceânico sob a variabilidade temporal da precipitação no Nordeste do Brasil. Revista Brasileira de Climatologia, v. 18, p.276-292, 2016.

PERNAMBUCO. Programa de Ação Estadual de Pernambuco para o Combate à Desertificação e Mitigação dos Efeitos da Seca - PAE-PE. Recife: CEPE, 2009.

PERNAMBUCO. Atlas de bacias hidrográficas de Pernambuco. Recife: Secretaria de Ciência, Tecnologia e Meio Ambiente, 2006.

PERNAMBUCO. Plano estadual de recursos hídricos. Recife: Secretaria de Ciências, Tecnologia e Meio Ambiente, 1998.

ROLIM, G.S.; SENTELHAS, P.C.; BARBIERI, V. Planilhas no ambiente EXCEL TM para os cálculos de balanços hídricos: normal, sequencial, de cultura e de produtividade real e potencial. Revista Brasileira de Agrometeorologia, v. 6, n.1, p133-137, 1998. 
SANTOS, C. A.; BRITO, J. I. B.; RAO, T. V. R.; MENEZES, H. E. A. Tendências dos Índices de Precipitação no Estado do Ceará. Revista Brasileira de Meteorologia, v.24, n.1, p.39-47, 2009.

SANTOS, C. A.; BRITO, J. I. B. Análise dos índices de extremos para o semiárido do Brasil e suas relações com TSM e IVDN. Revista Brasileira de Meteorologia, v. 22, n.3, p. 303-312, 2007.

SENA, J. P. O.; LUCENA, D. B. Identificação de tendência da precipitação na Microrregião do Cariri Paraibano. Revista Brasileira de Geografia Física, v.6, n.5 p. $1400-1416,2013$.

SILVA, W. S. [et al.,]. Teste sazonal de Mann Kendall para detectar tendências nas séries temporais de temperatura e umidade relativa do ar na cidade de Uberlândia MG. In: ENCONTRO MINEIRO DE ESTATÍSTICA - MGEST, 12., 2013, Uberlândia. Anais... Uberlândia: UFU, 2013.

SILVA, R. A. [et al.,]. Estudo da variabilidade da radiação solar no Nordeste do Brasil. R. Bras. Eng. Agríc. Ambiental, v.14, n.5, p.501-509, 2010.

THORNTHWAITE, C. W.; MATHER, J. R. The water balance. Centerton, N. J.: Drexel Institute of Technology, Laboratory of Climatology, publications in Climatology. v. 8, n. 1, New Jersey, 104 p., 1955.

THORNTHWAITE, C. W. Atlas of climatic types in the United States (1900-1939). Washington: United States Department of Agriculture, Soil Conservation Service, 1941. (Miscellaneous Publication, 421).

THORNTHWAITE, C. The Climates of the Earth. Geographical Review, v. 23, p.433-440, 1933.

THORNTHWAITE, C. The Climates of North American according to a new classification. Geographical Review, v. 21, p.633-655, 1931.

VASCONCELOS SOBRINHO, João de. Metodologia para identificação de processos de desertificação. Recife: SUDENE-DDL, 1978.

WMO. World Meteorological Organization. Standardized Precipitation Index: User Guide. 2012. Disponível em: <http://www.wamis.org/agm/pubs/SPI/WMO_1090_EN.pdf>. Acesso em: 12 Jul. 2016.

YUE, P. S.; YANG, T. C.; WU, C. K. Impact of climate change on water resources in southern Taiwan. Journal of Hydrology, v.260, p.161-175, 2002 